\section{A stable patient with a left ventricular assist device was admitted to the outpatient clinic with ventricular fibrillation}

\author{
Ömer Doğan (D), Şükrü Arsıan (D), Serhan Özyıldırım (D), Okay Abacı (DD \\ İstanbul University-Cerrahpaşa, Institute of Cardiology; İstanbul-Turkey
}

\section{Introduction}

A left ventricular assist device (LVAD) is used as a bridge therapy for transplantation in patients with advanced heart failure. Moreover, it can be used as a destination therapy for patients who are ineligible for heart transplantation (elevated pulmonary vascular resistance, cachexia, and renal insufficiency) or in the absence of appropriate donors. The use of such devices has become more popular recently owing to the increasing number of patients with medical treatment-refractory end-stage heart failure. Ventricular arrhythmias (VAs) are one of the most critical complications that develop in patients with LVAD. VAs are common in the first 30 days of LVAD implantation $(1,2)$. Although it has been reported that arrhythmias are generally well tolerated by patients with LVAD, their effects on mortality are still controversial. However, a general consensus states that VAs are the predictors of mortality in patients with LVAD (1-3).

\section{Case Report}

A 57-year-old male patient with a diagnosis of nonischemic dilated cardiomyopathy had a heart transplantation planned in 2012, and an LVAD (HeartMate II; Thoratec Corp., Pleasanton, California, United States of America) was implanted in the patient. The patient was admitted to our hospital outpatient clinic for routine control. He stated that he had not been able to check his peripheral pulse and measure his blood pressure (BP) with a BP monitor for the last month. During his physical examination, auscultation revealed no heart sounds, peripheral pulses were not palpable, BP was unmeasurable with a sphygmomanometer, and fine crackles were audible during late inspiration at the base of both the lungs. Neurological examination was normal. Rhythm monitoring and 12-lead electrocardiography revealed ventricular fibrillation (VF) as the cause of the sustained rhythm of the heart (Fig. 1a, 1b). Myocardial contraction was absent on echocardiography, and intense spontaneous echo contrast (SEC) was prominent in all chambers of the heart (Fig. 2a, 2b). The patient did not have an intracardiac cardioverter defibrillator and was admitted to the intensive care unit for electrical cardioversion. An intravenous bolus injection of $300 \mathrm{mg}$ amiodarone in $100 \mathrm{~mL}$ of $5 \%$ glucose was administered
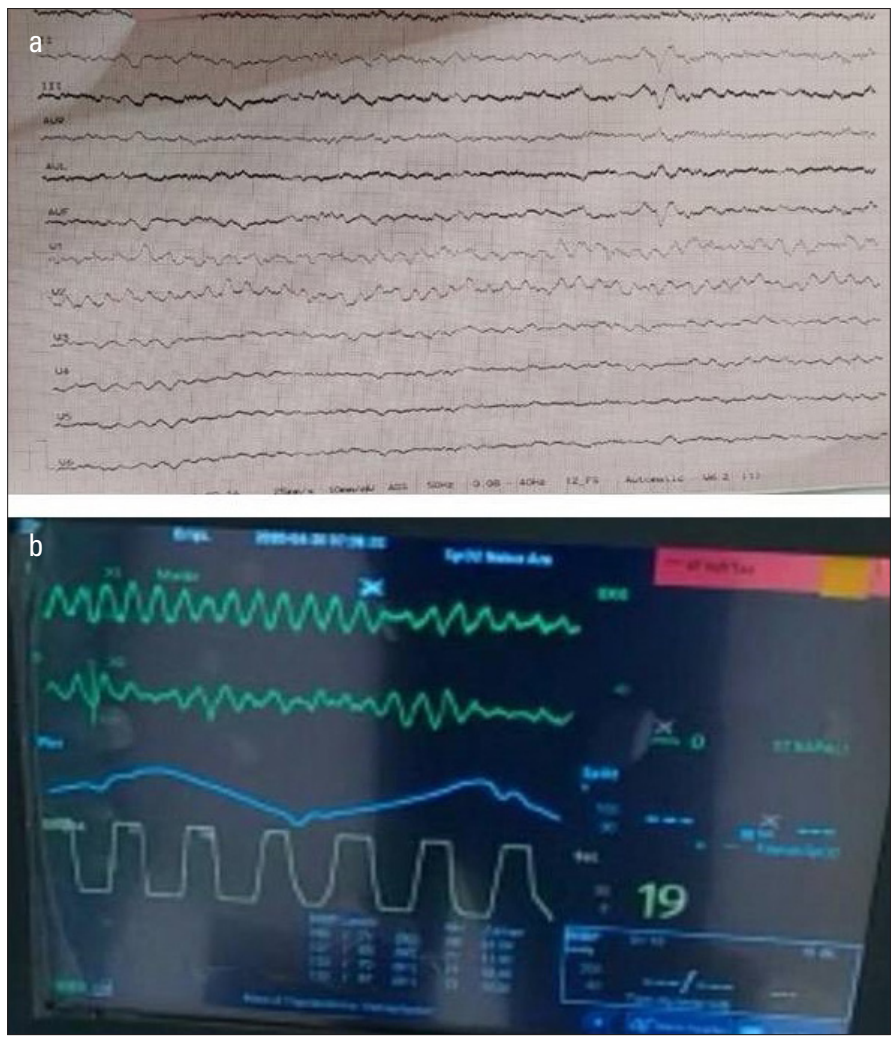

Figure 1. $(a, b)$ Electrocardiogram and monitor recording of the patient

over 20 minutes. Effective anticoagulation with an international normalized ratio of 2.9 necessitated no additional antithrombotic therapy before the procedure. After the failure of the first biphasic direct current $(D C)$ shock with $200 \mathrm{~J}$ following intravenous sedation, the second attempt with $270 \mathrm{~J}$ restored the sinus rhythm successfully. After cardioversion, the patient's systolic BP was $90 \mathrm{~mm} \mathrm{Hg}$ and heart rate was 82 beats per minute. On control echocardiography, the ejection fraction was $15 \%$ and all cardiac chambers were found to be dilatated; the findings were compatible with the left ventricular ejection fraction (LVEF) measurement conducted on echocardiography 3 months ago.

\section{Discussion}

Approximately $20 \%$ of patients with LVAD experience VAs, mostly ventricular fibrillation, after LVAD implantation (3). A history of preimplant VAs, atrial fibrillation, prior cardiac surgery, and nonischemic cardiomyopathy; heart failure duration prior to LVAD (>12 months); advanced age; scarring at the cannula insertion sites; pump suction rates; and electrolyte disturbances have been reported as the most common causes of arrhythmias that develop after LVAD implantation $(2,4,5)$. It has been reported that VAs are more common in the early period of LVAD implantation. In the literature, abnormal sinus rhythm owing to VF has been reported in a limited number of patients with LVAD during routine controls $(6,7)$. Such patients are generally admit- 

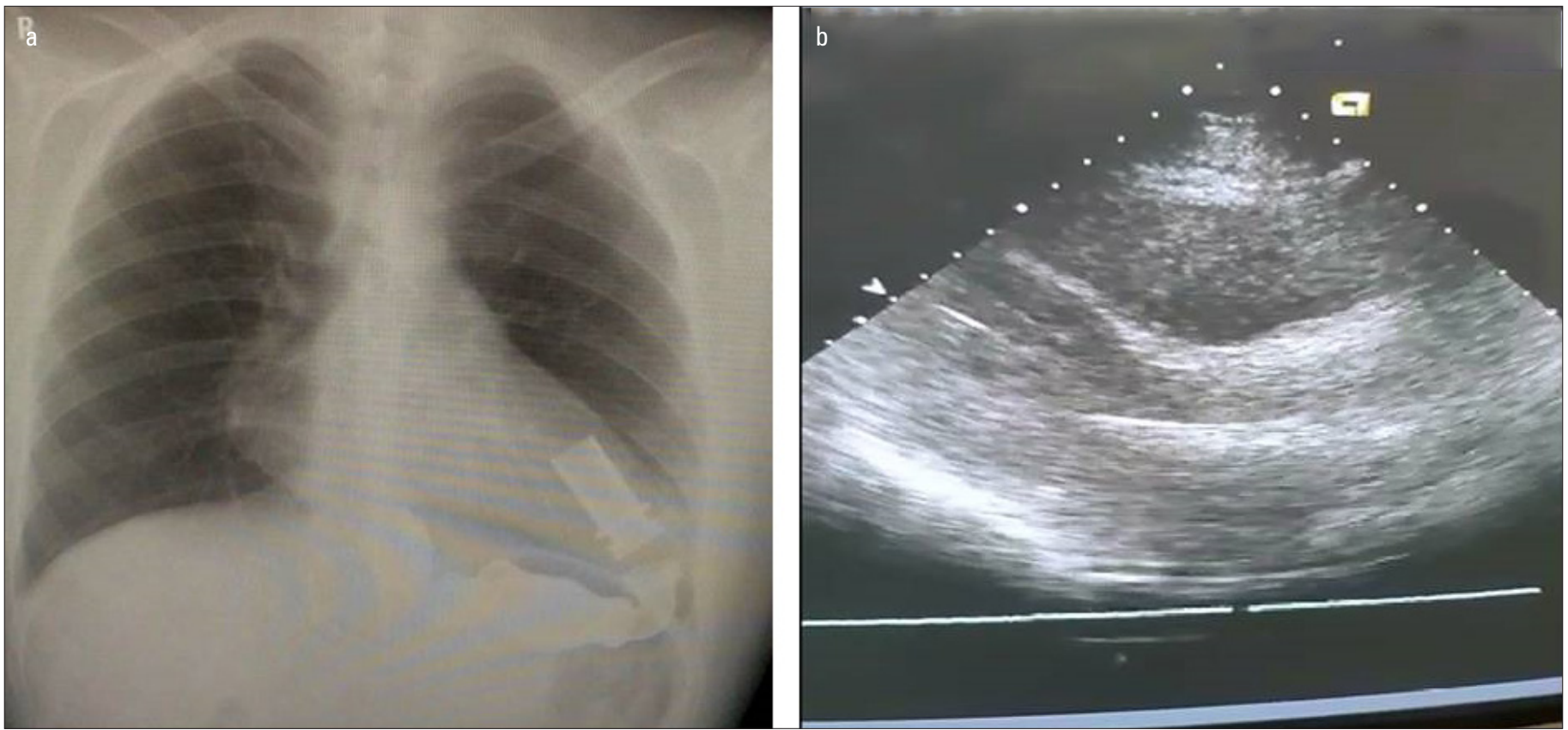

Figure 2. $(a, b)$ Telecardiogram of the patient with LVAD, parasternal long axis echo LVAD - left ventricular assist device

ted to hospital in the early period of VAs. Furthermore, in the case reviews of Baldwin et al. (8), VF that does not cause hemodynamic deterioration was reported in 6 patients. Among the 6 patients, three were diagnosed during their hospitalization period, and the other three were admitted to hospital in the early period of arrhythmia because of symptoms that occurred outside the hospital. In this study, it was reported that rhythm control was achieved by performing electrical DC cardioversion in all patients in the early period. In addition, the center reported that thrombus formation was observed in the aortic cusp and carotid bulb in continuous-flow LVADs.

In this case, we described the approach to VF detected in a patient with LVAD who complained of a lack of pulse and was unable to measure BP with a BP monitor for approximately a month without experiencing hemodynamic deterioration. The most striking aspect of this case is that the patient experienced VF for approximately a month and yet presented to the outpatient unit in a stable condition.

Continuous-flow LVADs impose thrombosis risk owing to the pump and other components in their structure. The risk of thrombus formation increases in case of inadequate anticoagulation, infection, atrial fibrillation, prolonged $V F$, and hypercoagulation (9-12). Pump dysfunction, hemolysis, embolism, paralysis, and death may occur as a result of thrombosis (9-11). Therefore, obtaining appropriate information regarding the anticoagulant status of such patients before performing cardioversion is important in order to provide additional anticoagulation if necessary (13). Another complication observed in patients with prolonged $V F$ is an increase in congestion findings owing to right ventricular dysfunction and subsequent hemodynamic deterioration (12).
Therefore, rhythm control should be maintained in such patients with electrical or medical treatment. Electrical cardioversion must be performed in patients with unstable hemodynamics. In patients with stable hemodynamics, electrical cardioversion can be performed in addition to medical therapy if arrhythmia persists after the elimination of volume replacement, electrolyte control, or other underlying causes (14). Catheter ablation is considered an appropriate approach, especially in case of a recurrence despite optimal medical therapy.

\section{Conclusion}

VAs are common and life-threatening arrhythmias in patients with end-stage heart failure. VAs are frequently encountered in patients with LVAD implantation, especially in the early period. LVADs help preserve hemodynamics in the early stages of VAs by supporting left ventricular functions. However, prolonged and delayed VAs may result in severe hemodynamic deterioration and thrombotic complications in patients with LVAD. In such cases, early rhythm control is important, especially in order to reduce the risk of thrombosis and to protect right ventricular functions. Therefore, during follow-up visits of patients with LVAD, close rhythm analysis with continuous monitoring systems such as implantable devices or smart watches and the evaluation of the current anticoagulation status at every visit is considered the most appropriate approach.

Informed consent: Informed consent was obtained from the patients for the publication of the case report and the accompanying images. 


\section{References}

1. Galand V, Flécher E, Auffret V, Pichard C, Boulé S, Vincentelli A, et al. Early Ventricular Arrhythmias After LVAD Implantation Is the Strongest Predictor of 30-Day Post-Operative Mortality. JACC Clin Electrophysiol 2019; 5: 944-54. [Crossref]

2. Maradey JA, Singleton MJ, O'Neill TJ, Bhave PD. Management of ventricular arrhythmias in patients with LVAD. Curr Opin Cardiol 2020; 35: 289-94. [Crossref]

3. Makki N, Mesubi O, Steyers C, Olshansky B, Abraham WT. MetaAnalysis of the Relation of Ventricular Arrhythmias to All-Cause Mortality After Implantation of a Left Ventricular Assist Device. Am J Cardiol 2015; 116: 1385-90. [Crossref]

4. Ahmed A, Amin M, Boilson BA, Killu AM, Madhavan M. Ventricular Arrhythmias in Patients With Left Ventricular Assist Device (LVAD). Curr Treat Options Cardiovasc Med 2019; 21: 75. [Crossref]

5. McLarty A. Mechanical Circulatory Support and the Role of LVADs in Heart Failure Therapy. Clin Med Insights Cardiol 2015; 9 (Suppl 2): 1-5. [Crossref]

6. Fasseas P, Kutalek SP, Kantharia BK. Prolonged sustained ventricular fibrillation without loss of consciousness in patients supported by a left ventricular assist device. Cardiology 2002; 97: 210-3. [Crossref]

7. Salzberg SP, Lachat ML, Zünd G, Turina MI. Left ventricular assist device (LVAD) enables survival during $7 \mathrm{~h}$ of sustained ventricular fibrillation. Eur J Cardiothorac Surg 2004; 26: 444-6. [Crossref]

8. Baldwin ACW, Gemmato CJ, Sandoval E, Cohn WE, Morgan JA, Frazier $\mathrm{OH}$. Tolerance of Sustained Ventricular Fibrillation During Continuous-Flow Left Ventricular Assist Device Support. Tex Heart Inst J 2017; 44: 357-60. [Crossref]
9. Potapov EV, Stepanenko A, Krabatsch T, Hetzer R. Managing longterm complications of left ventricular assist device therapy. Curr Opin Cardiol 2011; 26: 237-44. [Crossref]

10. Eckman PM, John R. Bleeding and thrombosis in patients with continuous-flow ventricular assist devices. Circulation 2012; 125: 3038-47. [Crossref]

11. Gurbel PA, Shah P, Desai S, Tantry US. Antithrombotic Strategies and Device Thrombosis. Cardiol Clin 2018; 36: 541-50. [Crossref]

12. Long B, Robertson J, Koyfman A, Brady W. Left ventricular assist devices and their complications: A review for emergency clinicians. Am J Emerg Med 2019; 37: 1562-70. [Crossref]

13. Feldman D, Pamboukian SV, Teuteberg JJ, Birks E, Lietz K, Moore SA, et al.; International Society for Heart and Lung Transplantation. The 2013 International Society for Heart and Lung Transplantation Guidelines for mechanical circulatory support: executive summary. J Heart Lung Transplant 2013; 32: 157-87. [Crossref]

14. Galand V, Flécher E, Auffret V, Boulé S, Vincentelli A, Dambrin C, et al.; ASSIST-ICD Investigators. Predictors and Clinical Impact of Late Ventricular Arrhythmias in Patients With Continuous-Flow Left Ventricular Assist Devices. JACC Clin Electrophysiol 2018; 4: 116675. [Crossref]

Address for Correspondence: Dr. Ömer Doğan, İstanbul Üniversitesi-Cerrahpaşa Kardiyoloji Enstitüsü, Kardiyoloji Anabilim Dalı, İstanbul-Türkiye

Phone: +90 5058976660

E-mail: omrdgn123@gmail.com

(c) Copyright 2021 by Turkish Society of Cardiology Available online at www.anatoljcardiol.com D0I:10.5152/AnatolJCardiol.2021.02009 